\title{
Short-term dynamics of sedimentary organic matter in a littoral area of the North Adriatic Sea (Italy): Evidence from ${ }^{234} \mathrm{Th}$ and ${ }^{7} \mathrm{Be}$
}

\author{
R. Guerra ${ }^{1,2}$ and S. Righi ${ }^{1,2}$ \\ ${ }^{1}$ Interdepartmental Centre for Environmental Science Research, Bologna University, \\ via S. Alberto 163, 48100 Ravenna, Italy \\ ${ }^{2}$ Department of Physics, Bologna University, Viale Pichat 6/2, 40127 Bologna, Italy
}

\begin{abstract}
In summer of 2007, short sediment cores $(<20 \mathrm{~cm})$ were collected in a littoral area of the North Adriatic Sea, Italy. Downcore measurements for radioactive tracers $\left({ }^{234} \mathrm{Th},{ }^{7} \mathrm{Be}\right)$ and organic matter signatures ( $\mathrm{OC}, \mathrm{TN}, \mathrm{C}: \mathrm{N}$ ratio) have been used to elucidate potential temporal changes in fluxes and cycles of organic matter in the area. Tracer distributions suggest that surface deposits throughout this area are rapidly reworked and this is supported by the findings of burrowing bivalves. Excess ${ }^{234} \mathrm{Th}$ was present at all stations, with surface activities $(0-1 \mathrm{~cm})$ ranging from 12 to $20 \mathrm{~Bq} / \mathrm{kg}$ and inventories of 46 and $166 \mathrm{mBq} \mathrm{cm}^{-2}$ with penetration depths of about $10 \mathrm{~cm}$. Steady-state particle mixing coefficients $\mathrm{D}_{\mathrm{b}}$ estimated using excess ${ }^{234} \mathrm{Th}$ ranged from $\sim 60$ to $150 \mathrm{~cm}^{2} \mathrm{yr}^{-1}$. The cores collected throughout the littoral system show a decrease in $\mathrm{OC}$ and TN down-core, and organic carbon signatures (OC and $\mathrm{C}: \mathrm{N}$ ) measured in sediment layers are indicative of multiple sources of sedimentary organic matter, where marine and estuarine phytoplankton is likely an additional important source of the direct input of organic matter.
\end{abstract}

\section{INTRODUCTION}

The distinction in time scales between temporary versus permanent storage of particulate material in bottom sediments is important in determining the ultimate fate of pollutants in coastal ecosystems. This difference in time scales can be distinguished quantitatively using radiotracers for establishing geochronologies within bedded sediments, and for examining rates of sedimentary processes. ${ }^{7} \mathrm{Be}$ is delivered to the surface of the earth through precipitation (wet and dry) where it quickly adsorbs to particle surfaces and is subsequently deposited to bottom sediments in coastal environments. In contrast, ${ }^{234} \mathrm{Th}$ is produced in the water column through the decay of its parent ${ }^{238} \mathrm{U}$. For the purpose of this study (i.e. short-term deposition and bioturbation), the half-life of ${ }^{7} \mathrm{Be}\left(53.3\right.$ days) and ${ }^{234} \mathrm{Th}$ (24.1 days) enables them to be useful as particle tracers on time scales of days to months. Particle reactive radiotracers such as ${ }^{234} \mathrm{Th}$ and ${ }^{7} \mathrm{Be}$ have been extensively used to help distinguish the varying sedimentary processes affecting coastal systems [1]. These radiotracers have been used in a number of applications including measuring sediment flux, resuspension events, event and seasonal deposition and sediment mixing [2-6]. Detectable ${ }^{7} \mathrm{Be}$ at dept is indicative of recently discharged fluvial sediment on the seabed, whereas detectable ${ }^{234} \mathrm{Th}$ indicates rapid deposition of any type of suspended sediment (i.e. fluvial or resuspended shelf sediment). However, after deposition of this sediment, ${ }^{234} \mathrm{Th}$ will decay faster than ${ }^{7} \mathrm{Be}$ due to difference in their half-lives, and therefore penetration depth of ${ }^{234} \mathrm{Th}$ is commonly less than that of ${ }^{7} \mathrm{Be}$. Seabed sediments, especially near large river systems, commonly have ${ }^{234} \mathrm{Th}$ but not ${ }^{7} \mathrm{Be}$, because recently eroded particles are rarely transported to the marine environment, but arrive after a series of depositional and erosional events occurring within the river channel and the floodplains. The objectives of this study were: (1) to evaluate the inventories of particle-reactive tracers $\left({ }^{234} \mathrm{Th}\right.$ and ${ }^{7} \mathrm{Be}$ ) in bottom sediments in a littoral area of the North Adriatic Sea; (2) to use these tracers to understand the processes and mechanisms that control the transport, fate and mixing of sediments in 
this area associated with a freshwater river; and (3) to use $\mathrm{OC}$ and $\mathrm{C} / \mathrm{N}$ ratios as proxies to characterise input and sources of sedimentary organic matter. This study represents the first attempt to evaluate the short-term sediment dynamics in this littoral area of the North Adriatic Sea.

\section{MATERIALS AND METHODS}

\subsection{Field methods}

Box-cores were taken on July 27, 2007, and Plexiglas sub-cores were inserted simultaneously into boxcores to collect samples for radiochemistry and chemistry analyses. Sub-cores $(<20 \mathrm{~cm})$ were kept on ice on board and frozen until analyses. Cores were thawed for $24 \mathrm{~h}$, then sectioned into $1 \mathrm{~cm}$ intervals over the first $10 \mathrm{~cm}$, and sectioned into $2 \mathrm{~cm}$ intervals thereafter. Three aliquots of each interval were then divided to allow for: (1) gamma counting $\left({ }^{7} \mathrm{Be}\right.$ and ${ }^{234} \mathrm{Th}$ ), (2) determination of bulk density and loss of ignition, and (3) determination of sedimentary organic carbon content. Sampling sites were located on a littoral area of the North Adriatic Sea at increasing distance from the Lamone River estuary, at about $10 \mathrm{~m}$ water depth.

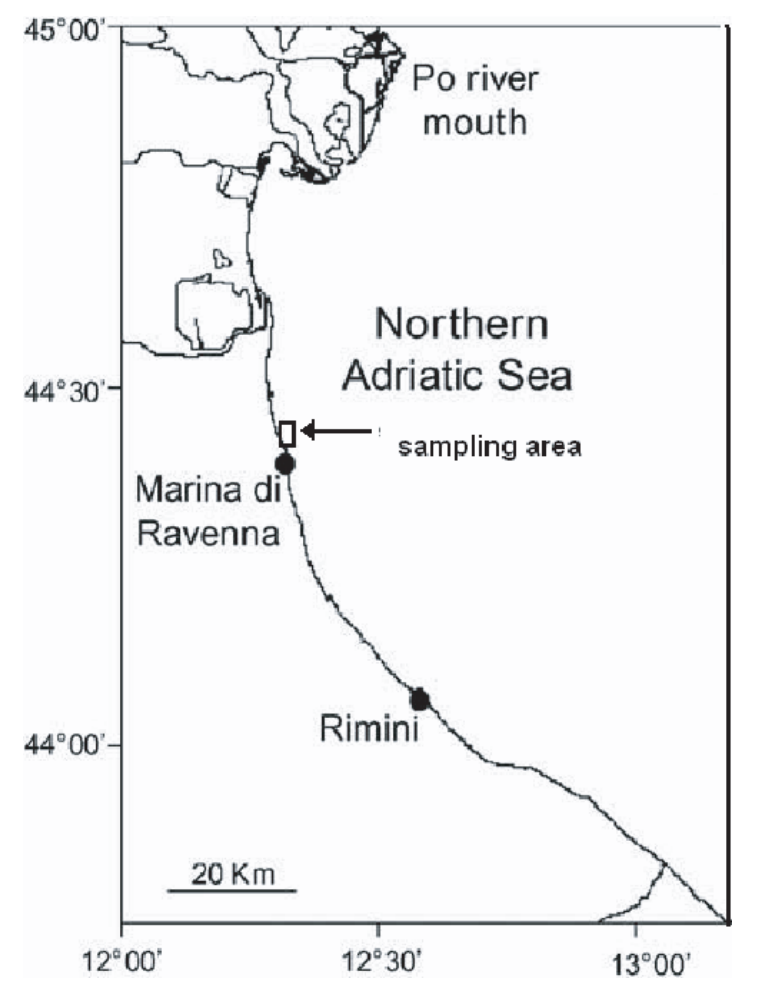

Figure 1. Map of the study area showing the sampling location of box cores collected during the summer of 2007.

\subsection{Laboratory methods}

Water content, porosity and wet and dry bulk densities were calculated from samples that were weighed before and after drying at $60^{\circ} \mathrm{C}$ until constant weight. Sediments were analyzed for organic carbon (OC) and total nitrogen (TN) following the methods of Hedges and Stern [7] in which dried sediments are acidified with $1.5 \mathrm{~N} \mathrm{HCl}$ to remove carbonate prior to analysis by a Carlo Erba Elemental Analyzer 
1108. Weight percentages of TN were determined similarly, but without acidification. Based on replicate measurements of standard reference sediments BCSS-1 and MESS-2, the average precision of the results was about $2-3 \%$ for OC. High-resolution gamma spectrometry was employed to resolve ${ }^{234} \mathrm{Th}$ $(\mathrm{E} \gamma=63 \mathrm{keV})$, and ${ }^{7} \mathrm{Be}(\mathrm{E} \gamma=477 \mathrm{keV})$ using a HPGe coaxial detector with an energy resolution (fullwidth at half-maximum) of $1.9 \mathrm{keV}$ at $1.33 \mathrm{MeV}\left({ }^{60} \mathrm{Co}\right)$, and a $22.6 \%$ efficiency. Wet sediment from each interval was sealed in Petri dishes with silicon, and $\gamma$-counted within few weeks after collection, to ensure that the short-lived radioisotopes were captured in the measurements. Detectors were calibrated using a natural matrix standard (DL-1a 'Reference Uranium Thorium Ore') at each energy of interest in the standard counting geometry for the associated detector. Excess ${ }^{234} \mathrm{Th}$ activities were calculated by subtracting the supported ${ }^{234} \mathrm{Th}$ activity (due to the decay of its parent ${ }^{238} \mathrm{U}$ in the seabed) from the total ${ }^{234} \mathrm{Th}$ activity. Supported activities were determined by re-counting samples after $\sim 5$ half lives $(\sim 125 \mathrm{~d})$, when all excess activity had decayed. In order to describe the fate of very recently deposited particles, it is possible to calculate inventories and bioturbation coefficients from ${ }^{234} \mathrm{Th}_{\mathrm{xs}}$ profiles. Bioturbation rates can be quantitatively derived from ${ }^{234}$ Th profiles according to Santschi et al. [8], where ${ }^{234} \mathrm{Th}$ is calculated as the difference between ${ }^{234} \mathrm{Th}_{(\text {total })}$ and supported ${ }^{234} \mathrm{Th}\left({ }^{234} \mathrm{Th}_{\text {supp }}={ }^{238} \mathrm{U}\right)$. Assuming steady state conditions, and the difference between ${ }^{234} \mathrm{Th}$ total and supported ${ }^{234} \mathrm{Th}$, the sediment-mixing coefficient $\left(\mathrm{D}_{\mathrm{b}}\right)$ can be calculated using the equation:

$$
\left[{ }^{234} T h_{x s}(z)\right]=\left[{ }^{234} T h_{x s}(0)\right] \exp \left(-\left(\lambda / D_{b}\right)^{1 / 2} z\right)
$$

where $D_{b}$ is the particle mixing coefficient (or bioturbation rate), in $\mathrm{cm}^{2} \mathrm{y}^{-1} ; \lambda$ is the decay constant of ${ }^{234} \mathrm{Th}\left(10.5 \mathrm{y}^{-1}\right)$; and $\mathrm{z}$ is the depth, in $\mathrm{cm}$. Sediment inventories of ${ }^{234} \mathrm{Th}$ (I) were calculated in $\mathrm{mBq} \mathrm{cm}{ }^{-2}$ from sediment-depth profiles according to the following:

$$
I=\rho_{s} X_{i}(1-\phi) A_{i}
$$

where $\rho_{s}$ is the mineral density $\left(2.65 \mathrm{~g} \mathrm{~cm}^{-3}\right), \mathrm{X}$ is the thickness $(\mathrm{cm})$ of the sampling interval $i, \phi$ is the porosity, and $\mathrm{A}$ is the activity $\left(\mathrm{mBq} \mathrm{g}^{-1}\right)$ of the sampling interval. The inventories were summed over continuous sediment intervals, each 1 or $2 \mathrm{~cm}$ thick.

\section{RESULTS AND DISCUSSION}

\subsection{Sedimentary organic matter}

The downcore variations of OC and TN content in sediments cores are displayed in Figure 2. In general, the \% OC content of sediment samples and sedimentary \% TN varied in the ranges $0.35-0.94 \%, 0.06-$ $0.09 \%$, and $0.44-1.36 \%, 0.07-0.13 \%$, in core S-1 and S-2, respectively. At both stations, TN profiles are shaped in a rather similar pattern of OC, showing a general decrease with depth with few exceptions. The exceptions were the bottom OC values found at a depth of $4-5 \mathrm{~cm}$ and $12-14 \mathrm{~cm}$ in core in cores $\mathrm{S}-1$ and S-2, respectively, which also reported the highest $\mathrm{C} / \mathrm{N}$ ratios observed for all samples (14.5 and 20.9).

Figure 3 provides an insight of $\mathrm{OC}$ content and $\mathrm{C} / \mathrm{N}$ ratio for the range of particulate matter, surface and core sediments, and autochthonous material sampled in North Adriatic Sea. Overall, the OC and C/N values found in this study showed a quite narrow distribution and averaged $0.57 \pm 0.21$ and $8.3 \pm 3.3$, respectively, with only 3 samples out of the main distribution, and this could imply there are multiple sources of organic carbon to the study area like terrestrial and riverine inputs, as well as estuarine and marine phytoplankton, each characterised by different $\mathrm{C} / \mathrm{N}$ ratio (Figure 3 ).

Information on the sources of $\mathrm{OC}$ is crucial for understanding the global carbon cycle in the area of study, but differentiation of multiple sources of organic matter requires further studies using elemental, isotopic and molecular biomarkers such as $\mathrm{C} / \mathrm{N}$ ratios and $\delta 13 \mathrm{C}$, which have been used to identify the 
a)

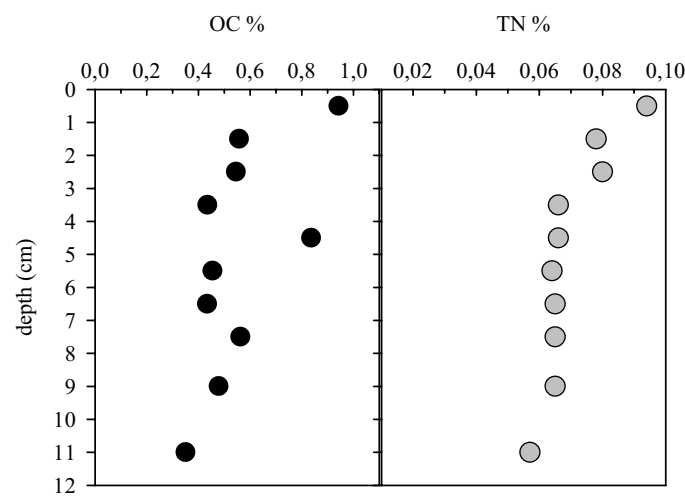

b)

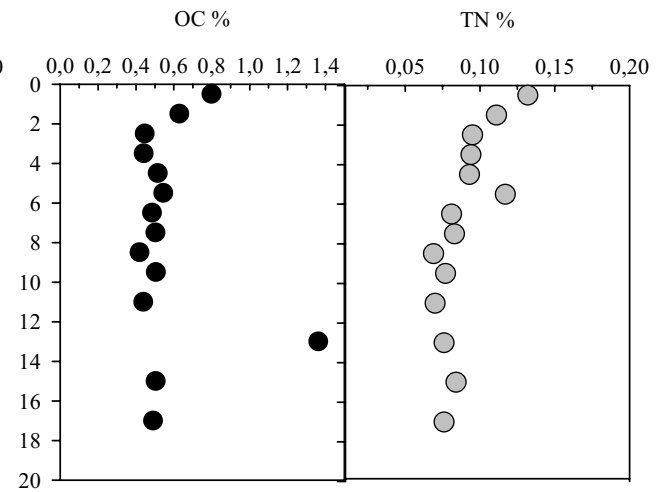

Figure 2. Vertical profiles of organic carbon (OC) content, and total nitrogen (TN) in sediment core S-1 (a) and in sediment core $\mathrm{S}-2$ (b).

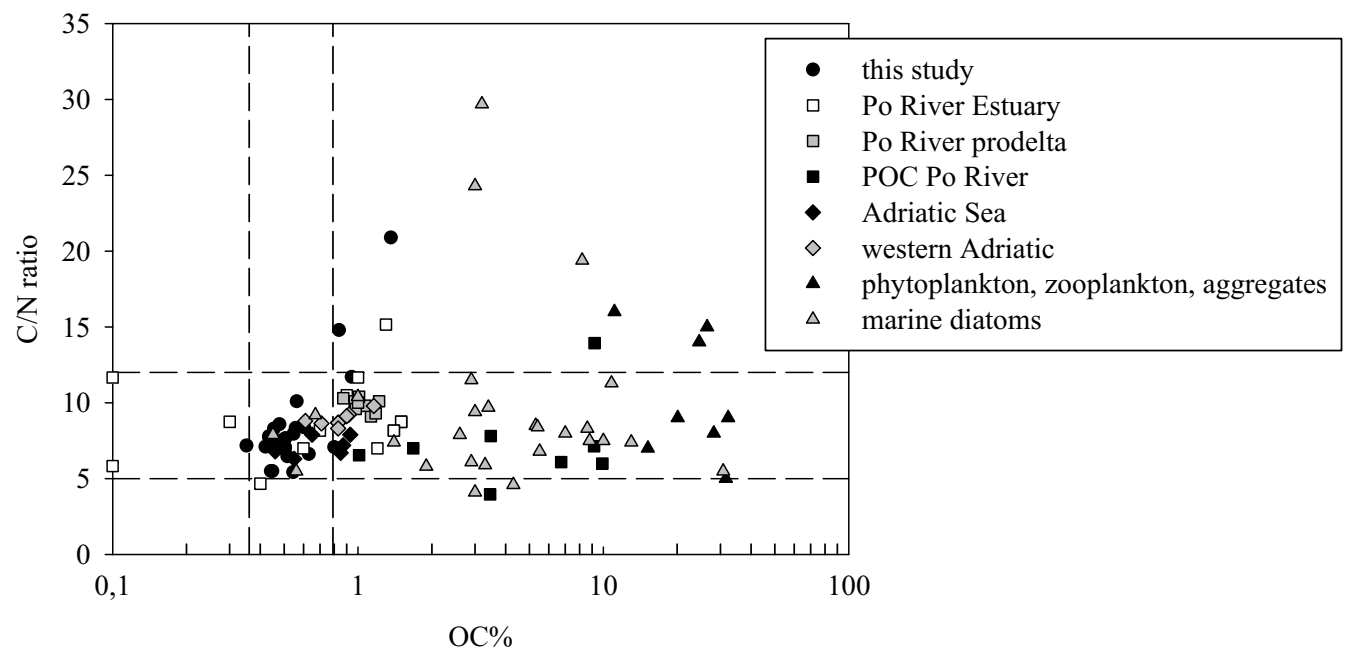

Figure 3. Relationship between $\mathrm{OC}$ and $\mathrm{C}: \mathrm{N}$ ratio for this study, the Po estuary and prodelta $[9,10]$, the Adriatic Sea [11] and western Adriatic [12, 13], the particulate organic carbon (POC) from the Po River [14], the marine phytoplankton, zooplanckton and mucilaginous aggregates sampled in the North Adriatic Sea [15], and marine diatoms [16].

allochthonous and autochthonous sources of organic matter to river-dominated continental shelves, such as the Adriatic [9, 12]. Nevertheless, the observations made in this study and by Tesi et al. [12] seems to indicate that in situ growth of marine and estuarine algae represents an additional important source of the direct input of OM.

\subsection{Short-term sedimentary dynamics: tracer distributions}

Short-term sedimentary dynamics were examined in the study area using two tracers having comparable half-lives. Figure 4 shows profiles of excess ${ }^{234} \mathrm{Th}$ and ${ }^{7} \mathrm{Be}$ activity versus depth in the seabed for each core and also shows the least calculated steady-state $D_{b}$ values from equation (1). ${ }^{234}$ Th activities are in excess of sedimentary ${ }^{238} \mathrm{U}$ at all stations due to addition of ${ }^{234} \mathrm{Th}$ from the water column. ${ }^{234} \mathrm{Th}$ from 
the overlying water is a possible source of ${ }^{234}$ Th to sediments; however, a likely contributor to seafloor patterns, and most excess ${ }^{234} \mathrm{Th}$ is derived from scavenging by particles in the water column. In general, at each station a surface zone of exponentially decreasing excess activity overlies a deeper region with either uniformly low activity or isolated activity peaks.

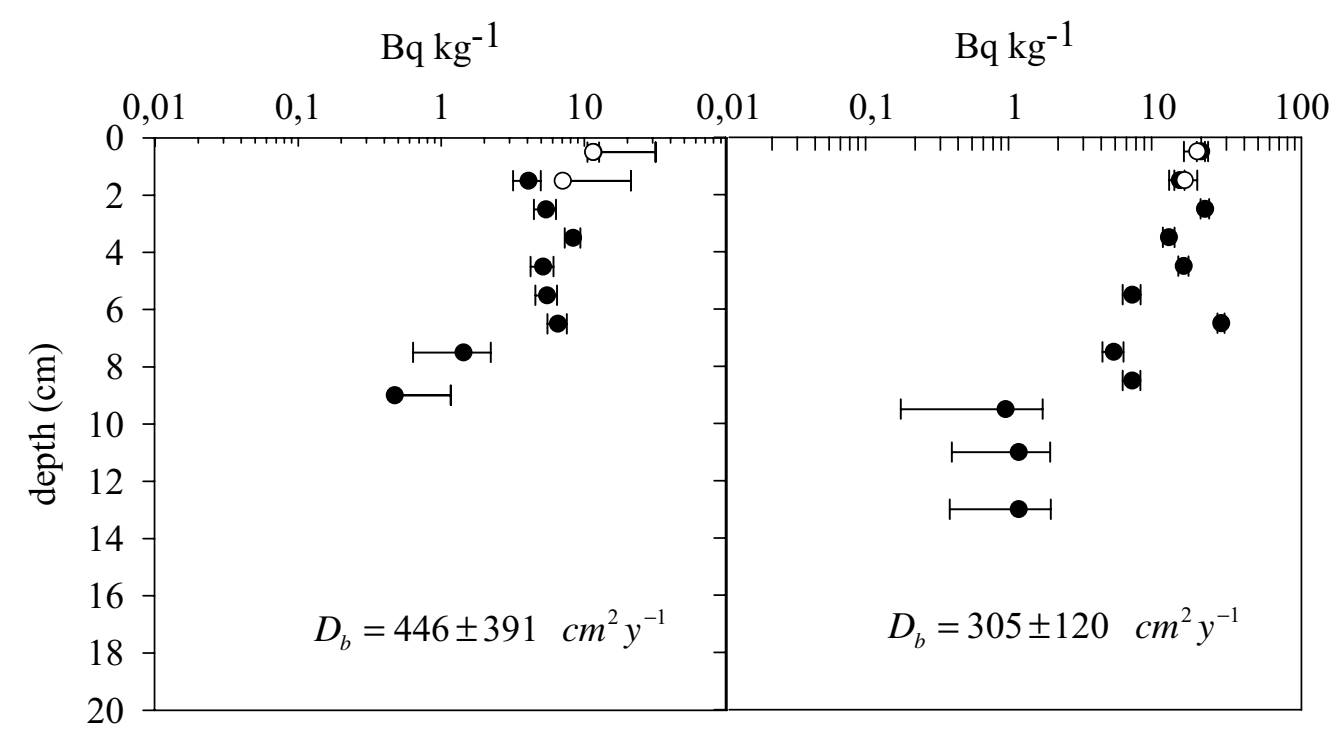

Figure 4. Profiles of ${ }^{234} \mathrm{Th}_{\mathrm{xs}}(\bullet)$ and ${ }^{7} \mathrm{Be}(\mathrm{\circ})$ in sediments cores $\mathrm{S}-1$ (left) and $\mathrm{S}-2$ (right).

The surface region is interpreted here as either uniformly mixed or perhaps rapidly deposited, and the underlying zone as subject to isolated non-local transport events on the time scale of ${ }^{234} \mathrm{Th}$ decay. Due to its very short half-life of 24 days, ${ }^{234} \mathrm{Th}_{\mathrm{xs}}$ should be present only at the water-sediment interface, however, both profiles show of ${ }^{234} \mathrm{Th}_{\mathrm{xs}}$ penetration depth of about $10 \mathrm{~cm}$. Radiotracers profiles also revealed that the penetration depths of ${ }^{234} \mathrm{Th}$ exceeded those of ${ }^{7} \mathrm{Be}$ in both cores. A possible explanation for the different penetration depths relates to the different sources of ${ }^{7} \mathrm{Be}$ and ${ }^{234} \mathrm{Th}$; in fact, when the material is stored in the drainage basin for $>200 \mathrm{~d}$ prior to delivery, its ${ }^{7} \mathrm{Be}$ signal will decay to below detection limits. The cause for the deeper penetration of ${ }^{234} \mathrm{Th}$ could be downward biological mixing of marine sediments with ${ }^{234} \mathrm{Th}$, and this is supported by laboratory observations of specimens of the blood clam Scapharca inaequivalvis in both cores, whose presence has been recorded in the North Adriatic Sea since 1972 [17], and implying that the sediments are actively being bioturbated. However, abundance and composition of the benthic community was not investigated in this study, which has been argued to be more relevant than tracer-derived mixing rates in determining the relative influence of organisms on bioturbation $[18,19] .{ }^{234} \mathrm{Th}_{\mathrm{xs}}$ inventories showed variations between sampling sites (46 and $123 \mathrm{mBq} \mathrm{cm}^{-2}$ for core S-1 and S-2, respectively), but are comparable to those found in other coastal systems $[1,20]$. The presence of ${ }^{234} \mathrm{Th}_{\mathrm{xs}}$ throughout the surface sediment layers on the study area is evidence of its deposition within the last $\sim 100$ days. Measurements of sediment mixing using ${ }^{234} \mathrm{Th}$, demonstrate that biological mixing coefficients $\mathrm{D}_{\mathrm{b}}\left(446\right.$ and $\left.305 \mathrm{~cm}^{2} \mathrm{y}^{-1}\right)$ are comparable to a range of sediment mixing coefficients commonly observed in other estuarine and continental shelf sediments [6, 8], and are higher than those found by Schmidt et al. [4, 5], Duport et al. [21], and Gerino et al. [22], but without time-series data on mixing rates in the area of study, the temporal consistency of $\mathrm{D}_{\mathrm{b}}$ is difficult to ascertain. When comparing the influence of bioturbation on vertical distribution and fate of sedimentary organic matter some hypothesis could be made. $\mathrm{C} / \mathrm{N}$ ratios have been used as a proxy for carbon quality with lower ratios indicating increased organic matter lability, which in turn, 
should result in an increase of macrofauna biomass contribution to diffusive mixing [19]. Bioturbation and deep mixed layer depths were recorded in this study, where sedimentary material had high $\mathrm{C} / \mathrm{N}$ thus indicating the refractory nature of organic material. Sediment disturbance due to activities of bivalves cannot be dismissed in this study considering that burrowing marine bivalves alter sediment loading, deposition, and stability patterns [23, 24], and Dauwe et al. [19] evidenced that the deep-living subsurface-deposit feeding bivalve Thyasira sp. is known to affect sediment chemistry and the fate of organic matter distribution in the sediment. Overall, our findings on short-term sedimentation dynamics over this littoral area of the North Adriatic Sea at a 100-day time scale based on isotopic tracers and sedimentary organic carbon proxies must be considered in this perspective when comparisons are made with other data, and should be corroborated with further investigation on macrofaunal densities and distribution, as well as with measurements of stable isotopic carbon signatures to detect the quality or provenance of sedimentary organic carbon.

\section{Acknowledgments}

This work could not have been carried out without the collaboration with of the Health Physics Service of Ravenna Hospital and the skilful technical assistance of Mirco Carnevali and Cesare Orlandi. The authors also wish to thank Dr. Alberto Righetti for his support, and for providing the boat and sampling equipment. Thanks are also extended to Dr. Daniele Serpentini for assistance with sample collection.

\section{References}

[1] D. Griffin and D.R. Corbett, J. Marine Syst 42, 83 (2003).

[2] M.M. Rutgers van der Loeff, R. Meyer, B. Rudels and E. Rachor, Deep-Sea Res I 49, 1941 (2002).

[3] C.M. Palinkas, C.A. Nittrouer, R.A. Wheatcroft and L. Langone, Mar Geo 222/223, 95 (2005).

[4] S. Schmidt, T.C.E. van Weering, J.-L. Reyss and P. van Beek, Prog Oceanogr 52, 331 (2002).

[5] S. Schmidt, J.-M. Jouanneau, O. Weber, P. Lecroart, O. Radakovitch, F. Gilbert and D. Jézequel, Estuar Coast Shelf S 72, 534 (2007).

[6] M.B. Dail, D.R. Corbett and J.P. Walsh, Cont Shelf Res 27, 1857 (2007).

[7] J.I. Hedges and J.H. Stern, Limnol Oceanogr 29, 45 (1984).

[8] P.H. Santschi, L. Guo, S. Asbill, M. Allison, A.B. Kepple and L.S. Wen, Mar Chem 73, 125 (2001).

[9] W. Martinotti, M. Camuso, L. Guzzi, L. Patrolecco and M. Pettine, Water Air Soil Poll 99, 325 (1997).

[10] S. Miserocchi, L. Langone and T. Tesi, Cont Shelf Res 27, 338 (2007).

[11] P. Giordani, W. Helder, E. Koning, S. Miserocchi, R. Danovaro and A. Malaguti, J Marine Syst 33-34, 365 (2002).

[12] T. Tesi, S. Miserocchi, L. Langone, L. Boni and F. Guerrini, Water Air Soil Poll 6, 593 (2006).

[13] T. Tesi, S. Miserocchi, M.A. Goñi, L. Langone, A. Boldrin and M. Turchetto, Estuar Coast Shelf S 73, 431 (2007).

[14] M. Pettine, L. Patrolecco, M. Camuso and S. Crecenzio, Estuar Coast Shelf S 46, 127 (1998).

[15] M. Giani, D. Berto, V. Zangrando, S. Castelli, P. Sist and R. Urbani, Sci Total Environ 353, 232 (2005).

[16] M.A. Brzerinski, J Phycol 21, 347 (1985).

[17] M. Monari, O. Cattani, G.P. Serrazanetti, A. Selli, G. Pagliuca, E. Zironi, S.C.M. O'Hara and D.R. Livingstone, Mar Environ Res 63, 200 (2007).

[18] S. Widdicombe, M.C. Austen, M.A. Kendall, R.M. Warwick and M.B. Jones, Hydrobiologia 440, 369 (2000).

[19] B. Dauwe. Organic matter quality in North Sea sediments. Ph.D. thesis (Univ. of Groningen, 1999). 
[20] C. Dubrulle, J.M. Jouanneau, P. Lesueur, J.F. Bourillet and O. Weber, Cont Shelf Res 27, 2099 (2007).

[21] E. Duport, F. Gilbert, J.-C. Poggiale, K. Dedieu, C. Rabouille and G. Stora, Estuar Coast Shelf S 72, 522 (2007).

[22] M. Gerino, M. Frignani, C. Mugnai, L.G. Bellucci, D. Prevedelli, A. Valentini, A. Castelli, S. Delmotte and S. Sauvage, Acta Oecol 32, 14 (2007).

[23] C.C. Vaughn and C.C. Hakenkamp, Freshwater Biol 46, 1431 (2001).

[24] L. Sgro, M. Mistri and J. Widdos, Hydrobiologia 550, 175 (2005). 
